A. Biason-Lauber $\cdot$ B. Boehm • M. Lang-Muritano •

B. R. Gauthier - T. Brun · C. B. Wollheim •

E. J. Schoenle

\title{
Association of childhood type 1 diabetes mellitus with a variant of PAX4: possible link to beta cell regenerative capacity
}

Received: 3 September 2004 / Accepted: 20 December 2004 / Published online: 15 April 2005

(C) Springer-Verlag 2005

\begin{abstract}
Aims/hypothesis: Loss of pancreatic beta cells is the crucial event in the development of type 1 diabetes. It is the result of an imbalance between autoimmune destruction and insufficient regeneration of islet cells. To study the role of islet cell regeneration in the pathogenesis of type 1 diabetes, we focused on PAX4, a paired homeodomain transcriptional repressor that is involved in islet cell growth. Methods: The study included 379 diabetic children and 1,070 controls from two distinct populations, and a cohort of children who had not developed type 1 diabetes, despite the presence of islet cell antibodies. Genomic DNA analysis of PAX4 was carried out via direct sequencing of PCRamplified fragments and allelic discrimination. We compared the transrepression potential of the PAX4 variants in $\beta T C 3$ cells and analysed their influence on beta cell growth. Results: The type 1 diabetic subjects are different from the normal individuals in terms of the genotype distribution of the $A 1168 C$ single nucleotide polymorphism in PAX4. The $C / C$ genotype is frequent among type 1 diabetic children $(73 \%)$ and rare among the control population (32\%). Conversely, the $A / C$ genotype is prevalent among control subjects $(62 \%)$ and antibody-positive children without type 1 diabetes (73.6\%), but uncommon among subjects with type 1 diabetes (17.5\%). The combination of PAX4A and PAX4C is functionally more active than $P A X 4 C$ alone (the 'diabetic'
\end{abstract}

\footnotetext{
A. Biason-Lauber $(\bowtie) \cdot$ M. Lang-Muritano $\cdot$ E. J. Schoenle Department of Paediatric Endocrinology/Diabetology, University Children's Hospital,

Steinwiesstrasse 75 ,

8032 Zurich, Switzerland

e-mail: Anna.Lauber@kispi.unizh.ch

Tel.: +41-1-2667623

Fax: $+41-1-2667169$

B. Boehm

Ulm University,

Ulm, Germany

B. R. Gauthier · T. Brun · C. B. Wollheim University Medical Centre,

Geneva, Switzerland
}

variant). Beta cells expressing $P A X 4 A$ and $P A X 4 C$ efficiently proliferate when stimulated with glucose, whereas cells expressing the PAX4C variant alone do not. Conclusions/ interpretation: We have identified a link between beta cell regenerative capacity and susceptibility to type 1 diabetes. This finding could explain the fact that not all of the individuals who develop autoimmunity against beta cells actually contract the disease. The $C / C$ genotype of the $A 1168 C$ polymorphism in $P A X 4$ can be viewed as a predisposition marker that can help to detect individuals prone to develop type 1 diabetes.

Keywords Diabetes mellitus, type $1 \cdot$ Pancreas Regeneration

Abbreviations BrdU: 5-bromo-2'-deoxyuridine · SNP: single nucleotide polymorphism

\section{Introduction}

The central event in type 1 diabetes mellitus is the selective loss of insulin-producing pancreatic beta cells. Type 1 diabetes can therefore be viewed as the result of an imbalance between autoimmune beta cell destruction and beta cell regeneration. Classically, the development of type 1 diabetes is divided into different stages, from genetic predisposition, to triggering, active autoimmunity and, finally, progressive beta cell destruction [1]. The extensively documented polygenic inheritance pattern of type 1 diabetes suggests that alterations in risk-modifying genes could lead to the eventual clinical manifestation of the disease. Specifically, alterations in these genes should play a role in the pathology of the disease, i.e. beta cell destruction (primarily due to immune mechanisms), decreased beta cell proliferation, and insufficient insulin secretion in response to stimulators such as glucose.

The mechanisms involved in the autoimmune destruction of beta cells have been extensively studied over the past three decades $[2,3]$, whereas the factors involved in islet cell development and regeneration have only recently 
been described and investigated (for reviews see $[4,5]$ ). Agents involved in organogenesis and differentiation of the pancreas are also likely to be involved in the processes of regeneration. Among these regulators, the transcription factor Pax 4 plays a crucial role in pancreatic beta cell development. The Pax family of transcription factors contain a paired box and a homeobox domain, and are essential for the formation of several tissues present in all germ layers in the mammalian embryo. Specifically, they are involved in triggering the early events of cell differentiation during organogenesis. The differentiation of endoderm-derived endocrine pancreas is mediated through Pax 4 and Pax6 [6]. Inactivation of pax4 by homologous recombination in mice results in the absence of mature insulinproducing beta cells and somatostatin-producing delta cells, and hyperplasia of glucagon-producing alpha cells [7]. The main function of Pax4 is as a transcriptional repressor in early pancreatic development $[8,9]$. The mechanism by which Pax4 influences beta cell function is not well understood. Activin A (a member of the TGF- $\beta$ family) stimulates Pax4 expression in pancreatic cell lines [10], and simultaneously promotes the growth and differentiation of human fetal pancreatic cells when combined with another growth factor, betacellulin [11]. These findings indicate that Pax4 is involved in the promotion of beta cell proliferation by growth factors. Although initial investigations suggested that PAX4 was not expressed in mature endocrine cells, more recent studies have detected mRNA for the transcription factor in adult human, rat and mouse pancreatic islets [12-14]. We have previously demonstrated that low levels of pax 4 mRNA are expressed, and that production of these transcripts is induced by the mitogens activin A and betacellulin. Adenoviral-mediated overexpression of Pax4 in islets was shown to produce a 3.5 -fold increase in beta cell proliferation [15]. A central concept that emerged from this study is that Pax4 operates as a key regulator of adult beta cell mass by converging the replicating effect of several signal transduction pathways towards the Myc-Id2 cascade. In parallel, cells protect themselves from $c$-Myc-induced apoptosis by increasing Bcl-xL expression.

Genetic association studies in humans have reported an association between $P A X 4$ variants and type 2 diabetes [16, 17]; however, this does not appear to be a global phenomenon, since it could not be found in other populations [18]. The $A 1168 C$ single nucleotide polymorphism (SNP) we have examined has not been found to be linked to any form of diabetes. In a study on Scandinavian families, Holm et al. observed an association between type 1 diabetes and haplotypes at the PAX4 locus on chromosome $7 \mathrm{q} 32$ that, together with the ISL1 locus on chromosome 5q11-q13, constitutes a significant susceptibility factor for type 1 diabetes [19].

We hypothesised that PAX4 will be 'reactivated' to promote the growth of islet cells in response to their destruction. If such a mechanism exists and is functional, the pancreas would react to an immune attack by regenerating beta cells. In contrast, inefficient proliferation would not be able to counteract the ongoing destruction, eventually leading to type 1 diabetes. To gain insight into the possible role of PAX4 in the pathogenesis of type 1 diabetes, we first screened for mutations in PAX4 in children with type 1 diabetes, and then investigated the consequences of these mutations in beta cell lines.

\section{Subjects and methods}

Subjects We initially recruited 249 children with type 1 diabetes (male:female ratio $=0.53: 0.47$ ) and 424 normal control subjects of Swiss origin (male:female $=0.57: 0.43$ ), and subsequently extended the analysis to include an additional 130 diabetic subjects (male:female ratio $=0.56: 0.44$ ) and 646 normal control subjects (male:female ratio $=0.63$ : 0.37 ) from a distinct German population. Type 1 diabetes was diagnosed according to the criteria approved by the American Diabetes Association [20]. All patients tested positive for anti-islet cell antibodies. The control subjects were unrelated individuals who did not have a history of type 1 or type 2 diabetes in the first-degree family line. An additional group included 19 school children (age 6-17 years) who, despite anti-islet cell antibody positivity, had not developed diabetes within 16 years of follow-up [21]. Patients' data and samples were anonymised according to the Swiss law (SR 235.154 and 236.1), and their collection conformed to the guidelines set out by the internal review boards. All participants (or their parents) gave informed consent. All samples were analysed in a blind fashion.

Genetic analysis Genomic DNA was extracted from peripheral blood leucocytes using the QIAGEN blood and cell culture DNA kit (Hilden, Germany). PCR exonic amplification of PAX4 (accession no. CH236947.1) was performed, and direct cycle sequencing of the PCR products was carried out using the ABI Prism BigDye Terminators v.3 kit and an ABI Prism 310 Genetic Analyzer (Applied Biosystems, Rotkreuz, Switzerland). Allelic discrimination was performed using two different methods: (1) RFLP based on $H p h \mathrm{I}$ digestion (performed according to the manufacturer's instructions; New England Biolabs, Allschwil, Switzerland); and (2) an allelic discrimination assay using specific TaqMan MGB probes, with the results analysed on the ABI Prism 7,700 Sequence Detection System (Applied Biosystems; the sequences of the primers and probes used are available upon request). To further confirm the data, 20 samples per group per genotype were sequenced as mentioned above. Primer sequences and PCR conditions are available upon request (all primers were supplied by Mycrosynth, Balgach, Switzerland). Chi square, significance and relative risk were calculated using standard methods.

Expression studies To study the functional implications of the PAX4 variants, we developed an RT-PCR method using PAX4 mRNA ectopically expressed in peripheral blood leucocytes of normal subjects who were homozygous for either the $A$ or $C$ variant [22]. The two PAX4 cDNA variants were ligated into a pCMV-Script vector (Stratagene, Basel, Switzerland) and used for functional studies. Mouse $\beta$ TC3 (German Collection of Microorganism and Cell Cultures, 
Braunschweig, Germany), $\alpha \mathrm{TC} 1.9$ and NIH3T3 (American Type Culture Collection, Manassas, VA, USA) cells were cultured $\left(7.5 \times 10^{3}\right.$ cells) in regular DMEM medium (25 $\mathrm{mmol} / 1$ glucose; Life Technologies, Basel, Switzerland). As they reached $80 \%$ confluence (at $36 \mathrm{~h}$ ), the cells were transiently transfected with $P A X 4 A, P A X 4 C$ or a combination of the two at a $1: 1$ molar ratio, using $50 \mu \mathrm{g}$ of lipofectamine per $10 \mu \mathrm{g}$ of DNA per $60-\mathrm{mm}$ plate (Life Technologies). We used a construct containing promoter sequences of the rat insulin I gene $(-410 \mathrm{bp})$ cloned upstream of a firefly lucierfase cDNA (pFOXluc-410RIP1) as a reporter, and the control plasmid pFOXlucl (which is devoid of the target sequence). Both plasmids were generous gifts from M. German (University of California, San Francisco, CA, USA). To normalise for transfection efficiency, the constitutively active Renilla luciferase-containing pRL-SV40 vector (Promega, Wallisellen, Switzerland) was used in addition to pFOXluc-410RIP1. Luciferase activity was measured $48 \mathrm{~h}$ after transfection using the Dual-Luciferase Reporter Assay System (Promega) as suggested by the supplier. All results are expressed as luciferase activity relative to control (where no PAX4=1). Total protein content was measured using the Bio-Rad Protein Assay (Hercules, CA, USA).

To study the influence of the PAX4 variants on cell growth, $7.5 \times 10^{3} \beta \mathrm{TC} 3, \alpha \mathrm{TC} 1.9$ and NIH3T3 cells were seeded on $35-\mathrm{mm}$ plates. Cells were then transfected with $P A X 4 A, P A X 4 C$, a combination of the two at a molar ratio of $1: 1$, or empty vector. The transfection efficiency, which was assessed using a $\beta$-galactosidase-containing vector (SV-40 $\beta$-gal; Promega), ranged from 40 to $60 \%$. At $48 \mathrm{~h}$ after transfection, the cells were cultivated for $12 \mathrm{~h}$ in the absence of glucose, and then exposed different concentrations of glucose $(0,5,15,25$ and $30 \mathrm{mmol} / \mathrm{l})$ for $12 \mathrm{~h}$, harvested, and counted in triplicate. To study the mechanism of putative changes in cell number, we used the same experimental design together with a commercial kit for analysis of proliferation, as directed by the supplier (Cell Proliferation ELISA, BrdU; Roche Applied Science). Briefly, the assay is based on the detection of 5-bromo2'-deoxyuridine (BrdU), an analogue of thymidine. Cells are labelled by the addition of BrdU for $4 \mathrm{~h}$. During this labelling period, BrdU is incorporated into the DNA of cycling cells in place of thymidine. After the removal of the labelling medium, an anti-BrdU antibody that binds to the BrdU incorporated into the newly synthesised DNA is added. The immune complexes are detected by the subsequent substrate reaction. The reaction product is quantified by measuring the absorbance using a scanning spectrophotometer (ELISA reader).

Electrophoresis mobility shift assay Nuclear extracts were obtained from transfected $\beta \mathrm{TC} 3$ cells $(48 \mathrm{~h}$ after transfection) as previously described [23]. The double-stranded oligonucleotides C2 (Top strand: 5'-AGCTGTGAGCAGG GACAGGTCTGGC-3') and DH1 (Top strand: 5'-AGCTG TGAGCAGGGACAGGTCTGGCCACCGGGCCCCTG$\left.3^{\prime}\right)$ [24] of the human insulin promoter, which are known to be target sequences for PAX4 were end-labelled with
$\left[\gamma^{32}\right.$-P]-ATP using T4 polynucleotide kinase. Binding assays were performed as previously described [23].

\section{Results}

Genetic findings The SNP in which an A or a $\mathrm{C}$ may be present in exon 9 of PAX4 (cDNA residue 1168; Table 1), corresponding to a proline or a histidine residue at position 321 in PAX4 protein, respectively $(P 321 H)$, was differentially distributed between control subjects and subjects with type 1 diabetes. As shown in Table 1, 63.5 and 61.4\% of normal Swiss and German individuals, respectively, were heterozygous, whereas 76.7 and $71.5 \%$ of the Swiss and German type 1 diabetic subjects, respectively, carried the $C / C$ genotype. Remarkably, $73 \%$ of children who had an anti-beta cell autoimmune reaction (islet cell antibodypositive) and carried the $A / C$ genotype still remain free of type 1 diabetes after 16 years of follow-up (Table 1). The relative risk of developing type 1 diabetes for carriers of the $C / C$ genotype is 3.75 -fold higher than for individuals carrying the $A / C$ or $A / A$ genotype. Subjects with the $A / C$ genotype have a five-fold lower chance of developing type 1 diabetes when compared with individuals carrying the other genotypes. In agreement with previous reports [18], no association was found between the A1168C SNP (P321H) and type 2 diabetes ( $n=344$, data not shown).

Functional implications To investigate potential functional differences between the PAX4 variants, we tested their transrepression potential in beta-like ( $\beta \mathrm{TC} 3)$, alpha-like $(\alpha \mathrm{TC} 1.9)$ and non-islet cells (NIH3T3). Compared with the $A$ variant, the PAX $4 C$ 'diabetic' variant was less effective at repressing the transcription of target sequences in insulinoma $\beta \mathrm{TC} 3$ cells. A combination of the two variants - a situation mimicking the control genotype- pro-

Table 1 Genotype frequencies of the $A 1168 C$ SNP in the study population

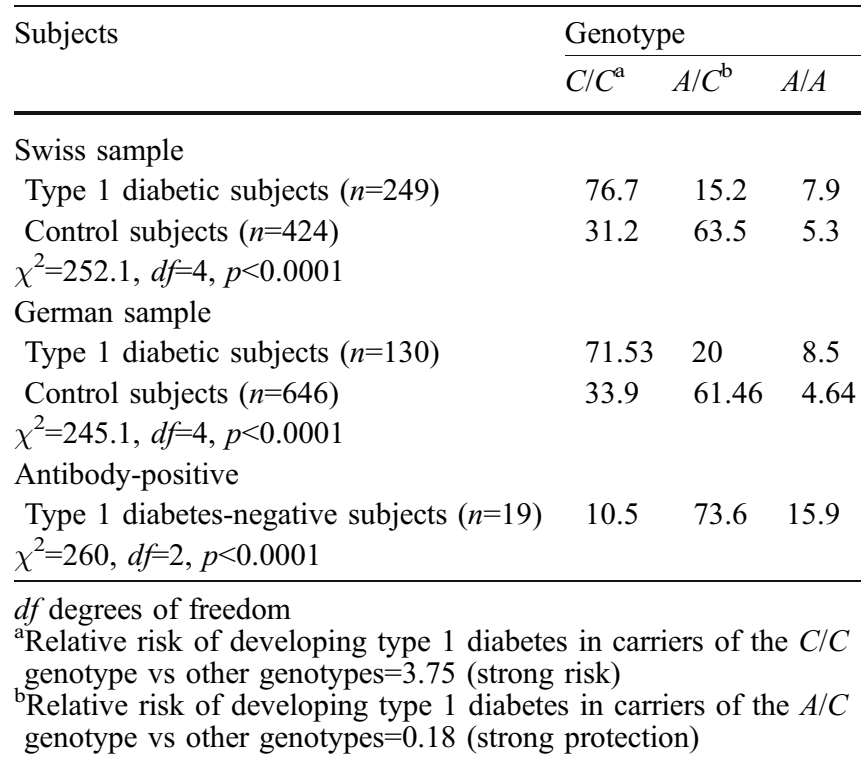


Fig. 1 Transcriptional activity of variants of human PAX4 in transfected $\beta$ TC 3 cells. Rat insulin I promoter sequences $(-410 \mathrm{bp})$ were cloned upstream of a firefly luciferase cDNA (pFOXluc-410RIP1) and transfected into $\beta$ TC3 cells, together with $P A X 4 C, P A X 4 A$ or a $1: 1$ mixture of the two. The same construct devoid of the target sequence was used as a control (pFOXluc). A constitutively active Renilla luciferase-containing construct (pRL-SV40) was used for standardisation purposes. As a control for background luminescence, the Renilla luciferasecontaining vector was transfected with or without $P A X 4 A$ and $P A X 4 C$. The data are expressed as relative luciferase activity (firefly/Renilla) (where no $P A X 4=1$ ). The results were subjected to statistical analysis (paired $t$-test). The data represent the means $\pm \mathrm{SD}$ of at least three independent experiments. $* p<0.05 ; * * p<0.02$; $* * * p<0.002 ; * * * * p<0.001$. Firefly, pFOXluc; Renilla, pRL-SV40; RIP, pFOXluc-410RIP1

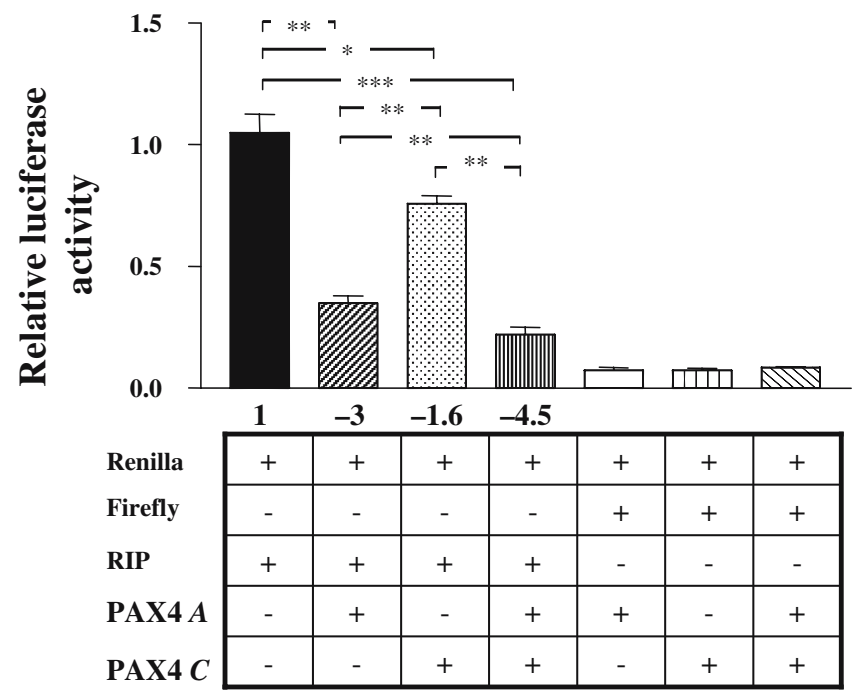

Fold repression duced the greatest level of repression (Fig. 1). This effect appears to be pancreas-specific, since similar results were obtained in $\alpha \mathrm{TC} 1.9$ cells but not in NIH3T3 cells (not shown). Compared with PAX4A, PAX4C appears to have an impaired ability to bind DNA target sequences (Fig. 2), even though the polymorphism may not be located within the DNA-binding domains. The combination of the $A$ and the $C$ variants appears to increase the DNA binding capacity of PAX4 (Fig. 2).

If $P A X 4$ variants play a role in the pathogenesis of type 1 diabetes, they may influence beta cell number and/or their

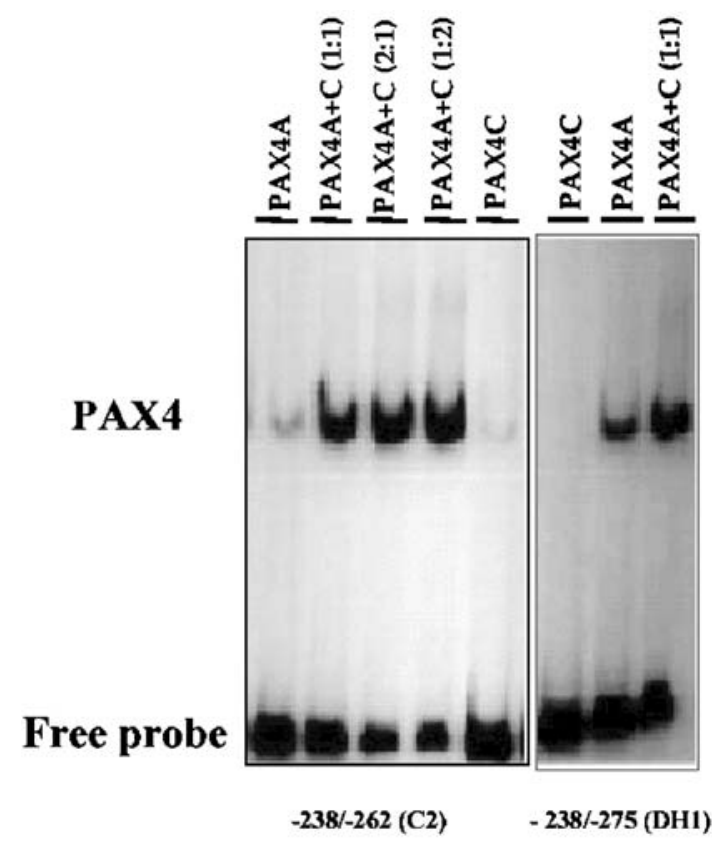

Fig. 2 The binding of the PAX4 variants to the human insulin promoter was analysed using an electrophoretic mobility shift assay. The oligonucleotides $\mathrm{C} 2$ and DH1 (corresponding to PAX4 target sequences on the human insulin promoter) were incubated with extracts from $\beta \mathrm{TC} 3$ cells transfected with $P A X 4 A$ and $P A X 4 C$, either alone or in combination at different molar ratios. The resultant protein-DNA complexes were visualised by electrophoresis differentiation. The cell count was increased by a factor of 2.5 at higher glucose concentrations $(15-25 \mathrm{mmol} / \mathrm{l})$ compared with that at lower concentrations $(0$ or $5 \mathrm{mmol} / \mathrm{l})$ (Fig. 3a). No further increase in the number of $\beta$ TC3 cells was seen at $30 \mathrm{mmol} / \mathrm{l}$ glucose (data not shown). The glucose-dependent increase in cell number was blunted in cells transfected with $P A X 4 C$, and this effect appeared to be overcome by the combination of $A$ and $C$. The effect of transfection with $P A X 4 A$ on the glucose-dependent increase in the number of $\beta \mathrm{TC} 3$ cells was not the same as that produced by transfection with the combination of $P A X 4 A$ and $P A X 4 C$ (Fig. 3a). The glucose-driven influence of PAX4 on cell number appears to be beta cell specific, as transfection with the PAX4 variants did not affect the cell count of $\alpha \mathrm{TC} 1.9$ cells or non-islet NIH3T3 cells (data not shown). The incorporation of BrdU into the newly synthesised DNA of replicating cells was significantly lower in $P A X 4 C$-transfected $\beta \mathrm{TC} 3$ cells than in cells expressing PAX4A either alone or in combination with $P A X 4 C$ (Fig. 3b). These results are consistent with those of the cell count experiments. The data suggest that the PAX4C 'diabetic' variant limits the proliferation of beta cells under glucose stimulation, the main physiological regulator of beta cell growth [21]. The addition of the $A$ to the $C$ variant (the control), restores the proliferation potential of these cells. The results indicate that the observed effects are mainly due to the overexpressed human PAX4 rather than the endogenous mouse Pax4 that is present in $\beta \mathrm{TC} 3$ cells, since the outcomes of all functional studies were more significant in the presence of human PAX4 than in its absence.

\section{Discussion}

In the present study we have demonstrated that there are differences between patients with type 1 diabetes and normal individuals in terms of the genotype distribution of the $A 1168 C$ SNP in PAX4. The differences were extremely striking: the majority of normal individuals were heterozygous, whereas most of the diabetic patients were homozy- 

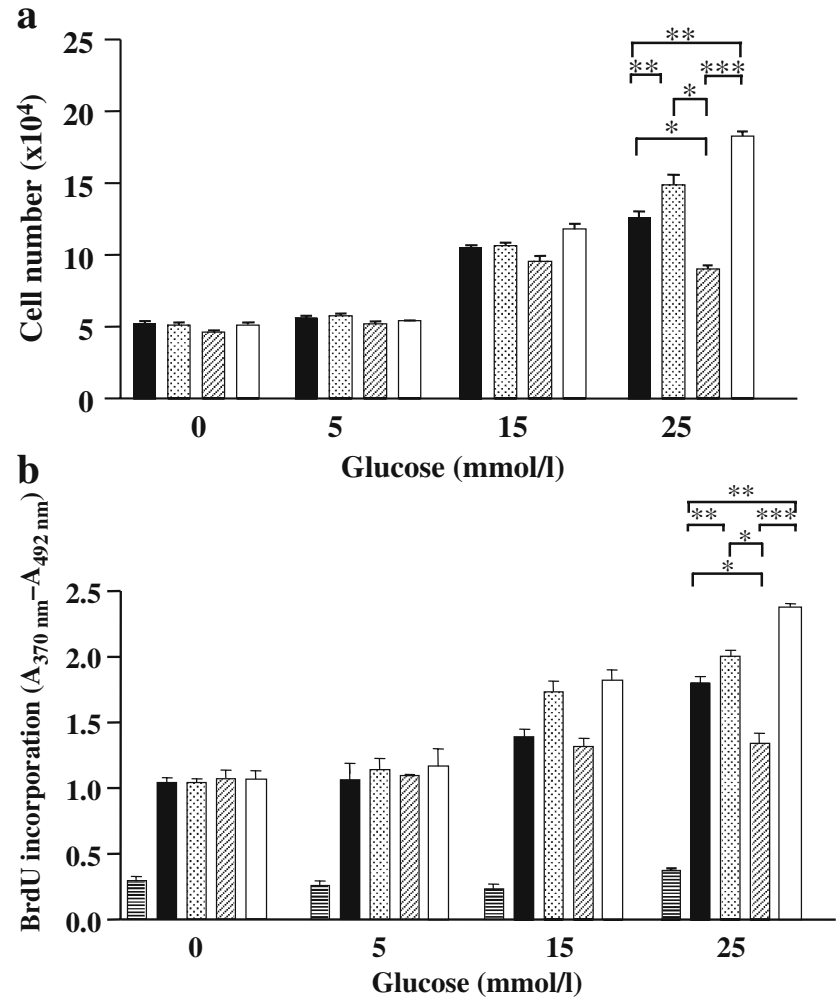

Fig. 3 a Effect of the overexpression of the $P A X 4$ variants on $\beta$ TC 3 cell number in the presence of increasing concentrations of glucose. The results were subjected to statistical analysis (paired $t$-test). $* p<0.05 ; * * p<0.02 ; * * * p<0.01$. The data represent the means \pm SD of at least three independent experiments. b Effect of the expression of the PAX4 variants on the proliferation of transfected $\beta T C 3$ cells, as measured by BrdU Cell Proliferation ELISA. The graph shows the incorporation of BrdU in adherent $\beta$ TC3 cells transfected with $P A X 4 A, P A X 4 C$, neither, or a combination of the two and cultured in 96-well microtitre plates under different concentrations of glucose (0-25 mmol/1). The rate of proliferation at higher glucose concentrations $(30 \mathrm{mmol} / \mathrm{l})$ is comparable to that at $25 \mathrm{mmol} / \mathrm{l}$. The data represent duplicate measurements of experiments performed in triplicate. The results were subjected to statistical analysis (paired $t$-test paired). ${ }^{*} p<0.05 ;{ }^{*} p<0.02 ;{ }^{* * *} p<0.01$. Blank, horizontal stripes; no PAX4, black fill; PAX4A, dotted fill; PAX4C, diagonal stripes; combination of $P A X 4 A$ and $P A X 4 C$, white fill

gous for the $C$ allele. The same results were demonstrated in two distinct populations, thus rendering a bias in the choice of the cohort less likely. The fact that a significant association between $P A X 4$ haplotypes and diabetes was recently described in a family-based Scandinavian study indicates that this is not an isolated phenomenon [19]. To investigate possible functional differences between the two variants, we tested their DNA binding capacity and transrepression potential. It appears that the PAX $4 C$ 'diabetic' variant is less active than the PAX $4 A$ variant in terms of binding and repressing target sequences. Transcription is repressed to the greatest extent when the two variants are combined (the situation mimicking the normal genotype). Although PAX $4 A$ seems to be the main regulator in alphalike cells, its role in beta cell function is at present unclear. The combination of the two variants seems to slightly increase their DNA binding capacity, which may explain the apparent heterozygote advantage. The basis of such phenomenon is at present unclear, since members of the Pax family of transcription factors are not known to form dimers.

If $P A X 4$ variants play a role in the pathogenesis of type 1 diabetes, they may influence the proliferation and/or differentiation of beta cells. The PAX4C 'diabetic' variant limits the proliferation of beta cells under glucose stimulation, the main physiological regulatory mechanism of beta cell growth [25]. The addition of the $A$ variant to the $C$ variant restores the proliferation potential of these cells. These data provide evidence for the loss of function of the 'diabetic' genotype $(C / C)$ and the protective function of the 'control' genotype $(A / C)$.

One of the implications that can be drawn from this study concerns possible preventive approaches for type 1 diabetes. Although the clinical onset of type 1 diabetes is acute, beta cell damage precedes clinical diabetes by several months or years. Two large randomised trials that aimed to control the destruction of beta cells have, unfortunately, yielded negative results. The Diabetes Prevention Trial-1 (DPT-1) failed to show any protective effect of insulin treatment [26], and in the European Nicotinamide Diabetes Intervention Trial (ENDIT), the administration of nicotinamide, which was hypothesised to attenuate DNA and beta cell damage, did not have any effect [27]. If beta cells cannot be protected from destruction, their regeneration potential could be used to counteract the ongoing attack. This seems to be achievable in the mature pancreas, since differentiated beta cells have been shown to have significant proliferative potential in vivo [28]. Further studies are required to improve our understanding of factors that predispose or protect against diabetes. This would allow the development of new assays that could be used in combination with those for previously identified markers in order to identify susceptible individuals. Our results indicate that the $C / C$ genotype of the $A 1168 C$ polymorphism in PAX4 is a diabetes susceptibility factor and might be used to detect individuals prone to develop type 1 diabetes. On the basis of our results we conclude that the combination of the two PAX4 variants may be involved in a process that has a protective effect against the onset of type 1 diabetes. This hypothesis is supported by the intriguing fact that children who tested positive for antibodies to beta cells and carried the $A / C$ genotype did not develop type 1 diabetes. Our results indicate a link between beta cell regenerative capacity and susceptibility to type 1 diabetes, which could explain the fact that only a certain proportion of individuals who develop autoimmunity against beta cells actually contract the disease. 
Acknowledgements This work was supported by the Swiss National Science Foundation (grant number 32-063629.0) and by a grant from Novo Nordisk Switzerland. B. Boehm was supported by the German Research Foundation (grant numbers DFG-GRK 1041, DFG-SFB 518) and by the Kröner-Fresenius Stiftung. We are grateful to M.S. German (University of California, San Francisco, CA, USA), for the generous gift of the reporter constructs pFOXluc-410RIP1 and pFOXluc1. We thank T. Torresani, B. Schäfer, B. Thöny and D. Konrad for critical discussion of the work, and M. Steigert and M. Gartenmann-Benz for their contributions. We are indebted to R. Zollinger and E. Alig for excellent technical assistance. We also acknowledge the continuous support of C.H. Heizmann.

\section{References}

1. Powers AC, Eisenbarth GS (1985) Autoimmunity to islet cells in diabetes mellitus. Annu Rev Med 36:533-544

2. Freiesleben De Blasio B, Bak P, Pociot F, Karlsen AE, Nerup J (1999) Onset of type 1 diabetes: a dynamical instability. Diabetes 48:1677-1685

3. Cooke A (1990) An overview on possible mechanisms of destruction of the insulin-producing beta cell. Curr Top Microbiol Immunol 164:125-142

4. Bonner-Weir S (2000) Life and death of the pancreatic beta cells. Trends Endocrinol Metab 11:375-378

5. Servitja JM, Ferrer J (2004) Transcriptional networks controlling pancreatic development and beta cell function. Diabetologia 47:597-613

6. Mansouri A, St-Onge L, Gruss P (1999) Role of Pax genes in endoderm-derived organs. Trends Endocrinol Metab 10:164167

7. Sosa-Pineda B, Chowdhury K, Torres M, Oliver G, Gruss P (1997) The Pax4 gene is essential for differentiation of insulinproducing beta cells in the mammalian pancreas. Nature 386 : 399-402

8. Smith SB, Ee HC, Conners JR, German MS (1999) Pairedhomeodomain transcription factor PAX4 acts as a transcriptional repressor in early pancreatic development. Mol Cell Biol 19:8272-8280

9. Fujitani Y, Kajimoto Y, Yasuda T et al (1999) Identification of a portable repression domain and an E1A-responsive activation domain in Pax4: a possible role of Pax4 as a transcriptional repressor in the pancreas. Mol Cell Biol 19:8281-8291

10. Ueda Y (2000) Activin A increases Pax4 gene expression in pancreatic beta cell lines. FEBS Lett 480:101-105

11. Demeterco C, Beattie GM, Dib SA, Lopez AD, Hayek A (2000) A role for activin A and betacellulin in human fetal pancreatic cell differentiation and growth. J Clin Endocrinol Metab 85:3892-3897

12. Heremans Y, Van De Casteele M, in't Veld P et al (2002) Recapitulation of embryonic neuroendocrine differentiation in adult human pancreatic duct cells expressing neurogenin 3. J Cell Biol 159:303-312

13. Kojima H, Fujimiya M, Matsumura K et al (2003) Neurodbetacellulin gene therapy induces islet neogenesis in the liver and reverses diabetes in mice. Nat Med 9:596-603
14. Zalzman M, Gupta S, Giri RK et al (2003) Reversal of hyperglycemia in mice by using human expandable insulinproducing cells differentiated from fetal liver progenitor cells. Proc Natl Acad Sci U S A 100:7253-7258

15. Brun T, Franklin I, St-Onge L et al (2004) The diabetes-linked transcription factor PAX4 promotes beta-cell proliferation in rat and human islets. J Cell Biol 167:1123-1135

16. Shimajiri Y, Sanke T, Furuta $\mathrm{H}$ et al (2001) A missense mutation of Pax 4 gene (R121W) is associated with type 2 diabetes in Japanese. Diabetes 50:2864-2869

17. Smith SB, Watada H, Scheel DW, Mrejen C, German MS (2000) Autoregulation and maturity onset diabetes of the young transcription factors control the human PAX4 promoter. J Biol Chem 275:36910-36919

18. Dupont S, Vionnet N, Chevre JC et al (1999) No evidence of linkage or diabetes-associated mutations in the transcription factors BETA2/NEUROD1 and PAX4 in Type II diabetes in France. Diabetologia 42:480-484

19. Holm P, Rydlander B, Luthman H, Kockum I (2004) Interaction and association analysis of a type 1 diabetes susceptibility locus on chromosome 5q11-q13 and the 7q32 chromosomal region in Scandinavian families. Diabetes 53:1584-1591

20. Report of the expert committee on the diagnosis and classification of diabetes mellitus (2003) Diabetes Care 26 [Suppl 1]: S5-S20

21. Schlosser M, Strebelow M, Wassmuth R et al (2002) The Karlsburg type 1 diabetes risk study of a normal schoolchild population: association of beta-cell autoantibodies and human leukocyte antigen-DQB1 alleles in antibody-positive individuals. J Clin Endocrinol Metab 87:2254-2261

22. Biason-Lauber A, Lang-Muritano M, Vaccaro T, Schoenle EJ (2002) Loss of kinase activity in a patient with WolcottRallison syndrome caused by a novel mutation in the EIF2AK3 gene. Diabetes 51:2301-2305

23. Schreiber E, Matthias P, Müller MM, Schaffner W (1989) Rapid detection of octamer binding proteins with 'mini-extracts', prepared from a small number of cells. Nucleic Acids Res 17:6419

24. Campbell SC, Cragg H, Elrick LJ, Macfarlane WM, Shennan KIJ, Docherty K (1999) Inhibitory effect of Pax4 on the human insulin and islet amyloid polypeptide (IAPP) promoters. FEBS Lett 463:53-57

25. Hellerstrom C, Swenne I (1985) Growth pattern of pancreatic islet in animals. In: Wolk BW, Arquilla ER (eds) The diabetic pancreas. Plenum Press, New York, pp 53-79

26. Diabetes prevention trial-type 1 diabetes study group (2002) Effects of insulin in relatives of patients with type 1 diabetes mellitus. N Engl J Med 346:1685-1691

27. Gale EA, Bingley PJ, Emmett CL, Collier T (2004) European nicotinamide diabetes prevention trial (ENDIT): a randomised controlled trial of intervention before the onset of type 1 diabetes. Lancet 363(9413):925-931

28. Dor Y, Brown J, Martinez O, Melton DA (2004) Adult pancreatic $\beta$-cells are formed by self-duplication rather than stem-cell differentiation. Nature 429:41-46 